\title{
Uma análise do desenvolvimento de alunos com deficiência intelectual em Feiras de Ciências
}

\author{
An analysis of the development of students with intelectual disabilities in Science \\ Fairs
}

Adriana Oliveira Bernardes ${ }^{1 *}$, Cesleste Azulay Kelman ${ }^{2}$

\begin{abstract}
RESUMO
Considerar várias formas de ensinar utilizando-se de recursos diversificados é algo que se almeja, não só para alunos que não apresentam problemas específicos, mas também para aqueles que possuem alguma deficiência. No universo da deficiência intelectual (DI), dependendo do nível de comprometimento do aluno DI, recursos como feiras de ciências precisam ser investigados e considerações a respeito do desempenho de tais alunos nas feiras são bem-vindas. O objetivo deste trabalho é discutir o desenvolvimento de alunos DI em feiras de ciências apartir do depoimento da professora de Física responsável pela coordenação do evento em colégio público estadual do Rio de Janeiro. O trabalho desenvolvido trata dos seguintes aspectos: desenvolvimento do aluno na parte de pesquisa bibliográfica, na apresentação do trabalho e na apresentação na feira propriamente dita. Da investigação participaram duas alunas DI matriculadas respectivamente no $2^{\circ}$ e $3^{\circ}$ ano do Ensino Médio. O trabalho mostra que as mesmas conseguem participar e alcançar bom desenvolvimento dentro de suasespecificidades, fazendo com que possamos qualificar o recurso supramencionado como inclusivo.
\end{abstract}

Palavras-chave: Ensino para alunos com Deficiência Intelectual; Feiras de Ciências; Educação Inclusiva.

\begin{abstract}
Considering various ways of teaching using diversified resources is something that is desired, not only for students who do not present specific problems, but also for those who have some disability. In the universe of intellectual disability (DI), depending on the level of commitment of the DI student, resources such as science fairs need to be investigated and considerations regarding the performance of such students at the fairs are welcome. The objective of this work is to discuss the development of DI students in science fairs from the testimony of the physics teacher responsible for coordinating the event in a state public school in Rio de Janeiro. The work developed deals with the following aspects: student development in the bibliographic research part, in the presentation of the work and in the presentation at the fair itself. Two DI students enrolled respectively in the 2nd and 3rd year of high school participated in the investigation. The work shows that they can participate and achieve good development within their specificities, so that we can qualify the aforementioned resource as inclusive.
\end{abstract}

Keywords: Teaching to students with Intellectual Disabilities; Science Fairs; Inclusive Education.

\footnotetext{
${ }^{1}$ Universidade Federal do Rio de Janeiro.

*E-mail:fisica.adrianabernardes@gmail.com

${ }^{2}$ Universidade Federal do Rio de Janeiro
} 


\section{INTRODUÇÃO}

Todos sabem que a simples inserção do aluno com deficiência na escola não irá colaborar necessariamente para seu desenvolvimento, e que além da inserção é necessário que, uma vez na escola, haja subsídios paraque o mesmo se desenvolva a partir de suas especificidades e, para isso, os diversos atores que compõem a comunidade escolar, como: professores, elementos da gestão, pais de alunos, funcionários e seus pares são fundamentais.

Neste contexto no qual consideramos o aluno com deficiência intelectual (DI) temos que: "O ideário inclusivo de trazer educandos com deficiências para as classes regulares, diminuindo consideravelmente o número de classes especiais para alunos com DI, deu-lhes uma oportunidade adicional de aprendizado. Não é uma atitude simples, pois tais pessoas enfrentam preconceito não só por parte dos colegas, mas também por parte de alguns de seus professores, que afirmam que elas não conseguem aprender”. (BERNARDES; KELMAN, 2018, p.4)

A própria Lei de Diretrizes e Bases da Educação (1996) reforça a ideia de que a escola forme um aluno cidadão e tal premissa não se restringe ao público considerado sem problemas especiais, mas também a alunos com deficiência. Deste ponto de vista, a convivência de todos os elementos que compõem a sociedade num contexto de respeito às diferenças é importante para que se possa dar oportunidade para que educandos com DI vivenciem situações em que exerçam sua cidadania, usufruindo de direitos e conhecendo seus deveres, o que é de se esperar em uma sociedade inclusiva.

Se avaliarmos as Metas para Educação no Século XXI (DELORS, 2010), observaremos a importância de que o aluno aprenda a conviver na escola com seus pares. Isso será de suma importância para o desenvolvimentode alunos com deficiência e deverá ser compreendido como alguém que sob algumas condições terá também chances de aprender e se desenvolver.

Neste sentido o documento de Delors traz as metas da educação parao século XXI e apresenta a seguinte discussão: 
A educação deve enfrentar esse problema porque, na perspectiva do parto doloroso de uma sociedade mundial, ela situa-se, mais do que nunca, no âmago do desenvolvimento da pessoa e das comunidades; sua missão consiste em permitir que todos, sem exceção, façamfrutificar seus talentos e suas potencialidades criativas, o que implica, por parte de cada um, na capacidade de assumir sua própria responsabilidade e de realizar seu projeto pessoal (DELORS, 2010, p.10).

Consideramos então que a sociedade precisa perceber a questão do aluno com deficiência de forma diferente e atuar efetivamente no sentido de fazer com que a escola busque caminhos para que sua inserção se dê de forma plena, envolvendo aprendizagem, ainda que parcial.

A Declaração de Madrid foi um documento tirado em 2002 por mais de 600 participantes de um evento organizado pela União Europeia, que proclamou o ano seguinte como o Ano Europeu das Pessoas com Deficiência. Buscava agir a nível local, regional e nacional dos países participantes. Essefoi mais um documento que se preocupou com a visão da necessidade de uma sociedade inclusiva, demandando a ruptura de barreiras sociais, uma vidaautônoma e a participação eficaz da família. A declaração conclui:

Legislações antidiscriminatórias provaram ser bem sucedidas para provocar mudanças de atitudes em relação a pessoas que têm deficiência. Contudo, a lei não é suficiente. Sem um forte compromisso de toda a sociedade, incluindo a participação ativa de pessoas com deficiência e suas organizações para defender seus direitos, a legislação permanece como uma concha vazia. Portanto, necessário educar o público para dar suporte às medidas legislativas, para aumentar a sua compreensão sobre os direitos e necessidades das pessoas com deficiência na sociedade e para combater preconceitos e estigmas que ainda existem nos dias de hoje (DECLARAÇÃO DE MADRID, 2002).

Considerando esse documento, observamos que a inclusão deveráadvir não só de uma sociedade que estabelece leis, ainda que as mesmas sejam importantes e que vários benefícios sejam provenientes delas, mastambém da educação dos membros da sociedade.

Em relação a tal questão da inclusão, o documento subsidiário da educação inclusiva aborda a seguinte questão:

Uma nova concepção de educação e sociedade se faz por vontade pública e é essencial que o sistema educacional assuma essa vontade. Para operar as transformações nos modos de relação dentroda escola é, também, necessário que os profissionais envolvidostomem para si a tarefa de pensar estas questões de forma reflexiva e coletiva. Dito de outra forma, é necessário que todos os agentes institucionais percebam-se como gestores e técnicos da educação inclusiva. (Documento subsidiário, 2005, p.23). 
Podemos através deste documento refletir sobre a importância de uma sociedade que lute por todos os elementos que a compõem, sem deixar delado as pessoas com deficiência. Acreditamos que para que o processo de inclusão na educação e na sociedade se dê, é fundamental que esta visão persista e se fortaleça. No ambiente escolar os profissionais da educação são atores fundamentais em busca de uma transformação da sociedade. O bom exercício de sua função contribui para a inclusão de alunos com deficiência.

É importante visualizarmos então que a educação especial inserida no universo escolar através do atendimento educacional especializado (AEE), que ocorre nas salas de recursos multifuncionais, devem estar presentes paratodos os segmentos de ensino que compõem a educação básica.

É necessário inclusive que se caminhe na perspectiva de visualizar uma escola num futuro próximo na qual a inclusão dos alunos em sala de aula seja tão eficaz que o mecanismo denominado educação especial presente na escola através das salas de atendimento especializado possa ser preterido. Isso já ocorre em vários países, como na Espanha. Existindo professores capacitados ao trabalho com alunos com variadas deficiências, que poderão prestar atendimento individualizado na sala de aula comum, sem que o aluno tenha que frequentar estruturas excludentes da educação especial.

A sala de AEE, embora auxilie o desenvolvimento das crianças com DI, colabora para que a escola afirme a necessidade de separação entre os educandos sem problemas específicos e os diferentes, baseada em uma perspectiva clínica (SILVA, 2011, p. 145).

\section{OBJETIVOS}

O objetivo deste trabalho é apresentar uma análise crítica sobre o desenvolvimento de duas alunas DIs, do $2^{\circ}$ e $3^{\circ}$ ano do Ensino Médio em feirasde ciências realizadas em escola pública do Rio de Janeiro, de 2016 à 2018, através do depoimento da professora coordenadora do evento.

\section{METODOLOGIA}


O trabalho que relatamos neste artigo foi realizado em colégio público estadual situado na cidade de Nova Friburgo, no estado do Rio de Janeiro.

O colégio conta com os turnos matutino, diurno e noturno e oferece Ensino Fundamental, Médio e Educação de Jovens e Adultos para aproximadamente 600 alunos.

A escola conta com um laboratório de Ciências, um laboratório de Informática e espaços físicos além da sala de aula, como auditório e quadra de esportes.

Realizamos uma análise do desenvolvimento das alunas nas feiras, de acordo com a avaliação da professora de Física responsável. O trabalho realizado pelos alunos podia ser realizado individualmente ou em grupo. A análise do desempenho foi feita em relação às seguintes tarefas: pesquisa inicial na internet desenvoltura para desenvolvimento das maquetes, apresentação em sala de aula e apresentação na Feira.

A professora em questão respondeu às seguintes perguntas:

1) Em relação à pesquisa realizada em livros e internet pelas alunas,como você considera o desenvolvimento das mesmas?

2) Em relação ao desenvolvimento de maquetes ou produto final, comovocê considera o desenvolvimento das mesmas?

3) Em relação à apresentação em sala de aula, como você considera o desenvolvimento das mesmas?

4) Em relação à apresentação na Feira, como você considera o desenvolvimento das mesmas?

\section{RESULTADOS}

O depoimento obtido através de conversa com professora foi o seguinte:

Em relação à primeira pergunta, segundo a professora:

"A pesquisa foi realizada sem maiores problemas pelas alunas e o material entregue, no qual constava a mesma, mostrava que havia sido feito deforma cuidadosa. A pesquisa foi realizada na sala de atendimento especializado, que conta com computadores".

Em relação à segunda pergunta, segundo a professora: 
"Houve dificuldades para confecção das maquetes sim! E alguns erros! Porém, o fato ocorre também com alunos que consideramos "normais". Porém, a elaboração da maquete propiciou a participação no evento sem maiores problemas, não chamando atenção dos jurados em relação aos problemas que apresentava”.

Em relação à terceira pergunta, segundo a professora:

“A apresentação em sala de aula foi ótima! Houve respeito dos colegas que também tem dificuldades nas apresentações. As dificuldades das mesmas não as distinguiram dos demais, muito pelo contrário. Causou surpresa aos colegas de classe, mostrando que as mesmas podiam ser integradas ao ambiente de aprendizado”.

Em relação à quarta pergunta, segundo a professora:

"Bom, as Feiras contam com a avaliação de jurados, então os mesmos foram informados a respeito da questão, já que eram pessoas externas a escola. Os jurados consideram importantíssima a participação delas e confirmaram que mesmo realizando leituras do tema, as mesmas davam pequenas explicações o que fazia com que o trabalho, em vista das especificidades das mesma, devesse ser incentivado".

\section{ANÁLISE DOS RESULTADOS}

Os dados obtidos, ainda que preliminares mostram que: as duas alunas participaram de todas as atividades que foram solicitadas. Isso é importante já que muitas atividades oferecidas não são realizadas com a justificativa de que não é possível sua realização.

Em relação à pesquisa realizada pelas alunas através da internet é destacado o desenvolvimento das mesmas, realizando a atividade sem grandes problemas, sendo que as mesmas foram alertadas a realizarem suas pesquisas preferencialmente em sites de universidades. Neste momento, a presença da professora da sala de atendimento especial foi importante para contribuir com a orientação adequada.

Em relação à elaboração da maquete a mesma foi realizada também na sala de recursos, alcançando bom resultado.

Em relação à apresentação em sala de aula, as mesmas se preocuparam em fazer uma boa apresentação. Realizaram leituras para alcançar esse objetivo. Consideramos 
que alunos sem problemas específicos também fazem isso. Logo, a atividade foi tida como satisfatória.

Da mesma forma. as apresentações realizadas para os jurados pelas alunas nas Feiras, foram consideradas satisfatórias, ainda que comparadas às apresentações dos demais alunos.

\title{
CONCLUSÃO
}

Neste trabalho mostramos a importância da utilização de recursos inclusivos pelos professores, os quais permitam o desenvolvimento dos alunos e sua inclusão na disciplina. Neste caso, consideramos o recurso Feira de ciências fortemente inclusivo.

Discutimos também como tal recurso pode ser utilizado por alunos DI de forma satisfatória, destacando as boas possibilidades de inclusão que a mesma proporciona. Porém, outros fatores são importantes além do recurso participação em Feiras. Um documento do MEC que subsidia a educação inclusiva atenta para a formação dos professores, afirmando que:

\begin{abstract}
A formação dos professores também ganha destaque entre asdemandas mais emergentes para o aprofundamento do processo de inclusão. Existe um consenso de que é imprescindível uma participação mais qualificada dos educadores para o avanço desta importante reforma educacional. O "despreparo dos professores" fi gura entre os obstáculos mais citados para a educação inclusiva, o qual tem como efeito o estranhamento do educador com aquele sujeito que não está de acordo com "os padrões de ensino e aprendizagem" da escola (MEC, 2005, p.28).
\end{abstract}

Sabemos que para inclusão dos alunos é fundamental a capacitação dos professores e seu engajamento para que se estabeleça na escola uma nova visão a respeito dos alunos com deficiência e que a partir daí sejarealizado um trabalho efetivo de inclusão.

Há que se pensar que a maioria dos professores não foram capacitados para realização de trabalho com alunos com deficiência e para queisso não se torne uma justificativa para o imobilismo, relatos como estes são importantes. Compartilhar e difundir experiências como a aqui narrada, podem servir de estímulo para que outros professores abordem a questão com um olhar mais positivo. 
Verificamos que as feiras de ciências são condizentes com o que se afirma a respeito das práticas escolares abaixo:

As práticas escolares que permitem ao aluno aprender e ter reconhecidos e valorizados os conhecimentos que é capaz de produzir, segundo suas possibilidades, são próprias de um ensino escolar que se distingue pela diversificação de atividades. O professor, na perspectiva da educação inclusiva, não ministra um "ensino diversificado" e para alguns. Ele prepara atividades diversas para seus alunos (com e sem deficiência mental) ao trabalhar um mesmo conteúdo curricular (MEC, 2007, p.7).

Neste contexto a Feira de Ciências é importante, já que permite a integração da diversidade de alunos presentes na escola, e dentre eles, o aluno com deficiência intelectual.

Uma das características importante das Feiras se deve ao fato de enfatizar o trabalho em grupo. Assim é explicitado no texto de Silva e Kalhil abaixo:

As atividades em grupo são estratégias que favorecem a aprendizagem dos alunos com DI e parcerias construídas de forma espontânea proporcionam condições para o diálogo entre eles e os professores. É um ganho para todos quando estes se posicionam ese tornam agentes ativos do processo. Desse modo, a avaliação do aluno com DI deve ser a mesma aplicada aos demais alunos, pois dessa forma se tornará mais justa (SILVA e KALHIL, 2017, 4195).

Devemos considerar que temos ainda um longo caminho em direção àeducação inclusiva e este caminho deve ser um caminho de reflexão realizada pelos professores. Este trabalho contribui para implementar valores inclusivosao expressar tal reflexão.

\section{REFERÊNCIAS}

ANTUNES, S. A Percepção da Comunidade Escolar sobre a Realidade das Pessoas com Deficiência Intelectual ou Múltipla.

Disponível em:http://www.ufpb.br/cia/contents/manuais/a-percepcao-dacomunidade-escolar- sobre-a-realidade-das-pessoas-com-deficiencia-intelectual-emultipla.pdf. Acesso em 10 de julho de 2018.

BRASIL. Lei no 9.396 (Lei de Diretrizes e Bases da Educação). Disponível em: http://portal.mec.gov.br/arquivos/pdf/ldb.pdf. Acesso em 7 março 2018.

BERNARDES, A. O. Algumas considerações sobre a importância das feiras de ciências. Revista Educação Pública, 2011. Disponível em: http://www.educacaopublica.rj.gov.br/biblioteca/educacao_em_ciencias/0006.html. Acesso em 23 nov. 2019. 
BERNARDES, A. O. A importância da elaboração de feiras de ciências como reflexo dotrabalho realizado em sala de aula.

Disponível em:http://educacaopublica.cederj.edu.br/revista/artigos/a-importancia-daelaboracao-de-feiras-deciencias-como-reflexo-do-trabalho-realizado-em-sala- de-aula

BERNARDES, Adriana O., KELMAN, Celeste Azulay. Ensinando Física a alunos com deficiência intelectual: em busca de um currículo mínimo estadual. In: III Cintedi 2018, Campina Grande PB. Disponível em: http://editorarealize. com.br/ revistas/cintedi/trabalhos/TRABALHO_EV110_MD1_SA17_ID2599 11082018202007.pdf. Acesso em 7 mar. 2018.

BRASIL. Documento Subsidiário de 2015, ORIENTAÇÕES PARA IMPLEMENTAÇÃO DA POLÍTICA DE EDUCAÇÃO ESPECIAL NA PERSPECTIVA DA EDUCAÇÃO INCLUSIVA: Disponível em:

http://portal.mec.gov.br/index.php?option=com_docman\&view=download\&alias $=17237$-secadi-documento-subsidiario-2015\&Itemid=30192. Acesso em: $10 \mathrm{de} \mathrm{fev.} \mathrm{de}$ 2019.

BRASIL. MEC. Atendimento Educacional Especializado. Disponível em: http://portal.mec.gov.br/seesp/arquivos/pdf/aee_dm.pdf. Acesso em: 10 de julho de 2018.

Convenções e Declarações da ONU sobre a Pessoa com Deficiência. Disponível em:http://www.ampid.org.br/ampid/Docs_PD/Convencoes ONU_PD. php. Acesso em 7 mar. 2018.

CASTRO, Mariana G. F. de; BERNARDES, Adriana O. Feira de Ciências: um recurso inclusivo. In: II Cintedi 2018, Campina Grande PB. Disponível em:https://editorarealize.com.br/revistas/cintedi/trabalhos/TRABALHO_EV060_MD 4_SA16_ID1393_28092016004203.pdf. Acesso em: 10 de fev. 2019.

DECLARAÇÃO DE MADRID. Documento tirado por países representantes daUnião Europeia, 2002.

DELORS, J. Educação: um tesouro a construir. Relatório da ComissãoInternacional sobre Educação para o Século XXI. Julho 2010. Disponível em:

http://unesdoc.unesco.org/images/0010/001095/109590por.pdf . Acesso em 7mar. 2018.

RIO DE JANEIRO. Currículo Mínimo Estadual de Física. Fevereiro de 2012.

SILVA, Fabrícia Gomes. Da Inclusão escolar de alunos com deficiência intelectual: o atendimento intelectual especializado (AEE) em discussão. Fortaleza, 2011, p. 166. Universidade Estadual do Ceará, Centro de Educação. 
SILVA, P.P.S. KALHIL, J.B. Uma proposta de metodologia de ensino de Física em turmas que possuem alunos com deficiência intelectual. X Congreso Internacional sobre Investigación en Didáctica. de las Ciências. Sevilla, España. 5-8 de septiembre de 2017. ISSN (DIGITAL): 2174-6486.

Recebido em: 20/10/2021

Aprovado em: 10/11/2021

Publicado em: 18/11/2021 